\title{
Microvasculature of Growing and Atretic Follicles in the Rabbit Ovary: A SEM Study of Corrosion Casts*
}

\author{
Guido Macchiarelli, Stefania A. Nottola, Enrico Vizza, Giuseppe Familiari ${ }^{1}$, Akio KikUta ${ }^{2}$, \\ Takuro Murakami ${ }^{2}$ and Pietro M. MotTa ${ }^{1}$ \\ Department of Anatomy ${ }^{1}$, Medical School, University of Rome "La Sapienza”, Rome, Italy; and Department of Anatomy², \\ University of Okayama, Medical School, Okayama, Japan
}

Received January 18, 1993

Summary. Rabbit ovarian microvasculature, with particular regard to developing and atretic follicles, was studied by scanning electron microscopy (SEM) of vascular corrosion casts.

The microvascular network of the follicles was arranged in typical round plexuses of varying shape and size. Four different morphological types of vascular plexuses supplied the follicles: Type $1(100-250 \mu \mathrm{m}$ in diameter) consisted of a simple net of thin capillaries that delimited a small empty central cavity. Type 2 (diameter $>250$ $\mu \mathrm{m})$ consisted of a multilayered capillary wall delimiting a large empty central cavity. This wall presented an inner layer made of uniformly distributed dilated and tortuous capillaries with numerous angiogenetic sprouts. Type 3 (diameter of 100-300 $\mu \mathrm{m}$ ) lacked the central cavity and comprised randomly arranged thin capillaries. Type 4 (diameter $>250 \mu \mathrm{m}$ ) consisted of a multilayered capillary wall delimiting a central cavity. Its inner layer was made of capillaries not homogeneous in size and course (thin in some areas, sinusoidal in others, sometimes highly dilated). In addition, the wall showed large interruptions (avascular areas) and focal invasion of the central cavity by newly formed vessels.

Types 1 and 2 showed the gradual transformation of thin capillaries into sinusoids as has been demonstrated in evolutive follicles. Types 3 and 4, described here for the first time, probably represent the vascular supply to atretic follicles. In particular, Type 3 supplied follicles undergoing obliterating atretic degeneration, whereas Type 4 supplied atretic follicles with hypertrophy of the theca layer. In fact, follicular atresia is a pleiomorphic phenomenon which ends in a regression of the follicles (obliterant atresia), but which may induce a temporary follicular hyperactivation (luteinizing atresia). These changes in the microvasculature prelude the formation of the so called "interstitial gland of the ovary". Further- more, these data prove that: 1) both thecal capillary vasodilatation and angiogenetic processes basically support the gradual increase of ovarian blood flow during follicle growth; 2) microvascular changes of atretic follicles are possibly related to a type of inflammatory reaction since they seem to be a consequential rather than primary cause of atresia.

The ovary continuously undergoes cellular and vascular changes due to the cyclical activity of the luteofollicular complex (MOTTA and VAN BLERKOM, 1974, 1975; VAN BLERKOM and MOTTA, 1978, 1979; MOTTA et al., 1992; MACCHIARELLI et al., $1992 \mathrm{a}, \mathrm{b}$ ).

Several SEM studies of vascular corrosion casts have been performed on the microvasculature of the luteofollicular complex in both normal and experimental conditions in rodents, horses, cows and sheep (KARDON and KESSEL, 1979; KANZAKI et al., 1982; KIKUTA et al., 1984; KITAI et al., 1985; SPANEL-BOROWSKY et al., 1987; HEEs et al., 1988; MURAKAMI et al., 1988; KÖNIG et al., 1989; MURDOCH and CAVENDER, 1989; OKAMURA, 1989; KIKUTA et al., 1991; MACCHIARELLI et al., 1991, 1992b). In particular, certain studies have dealt with the rabbit ovary's microvascular changes induced by ovulation in the follicles (KANZAKI et al., 1982; KITAI et al., 1985; OKAMURA, 1989) or in the interstitial stromal tissue (MACCHIARELli et al., 1991).

Developing follicles may halt their growth and undergo atresia (BYSKOV, 1978; GREENWALD and TERRANOVA, 1988; HUBBARD and OXBERRY, 1991). Indeed, atresia is the final fate of most ovarian follicles, and most atretic follicles transform into a temporary but highly func-

${ }^{*}$ Funds for this work were provided by M.U.R.S.T. (Faculty $40 \%$ and $60 \%$ ) and C.N.R., Italy, and the Ministry of Education, Science and Culture, Japan. 


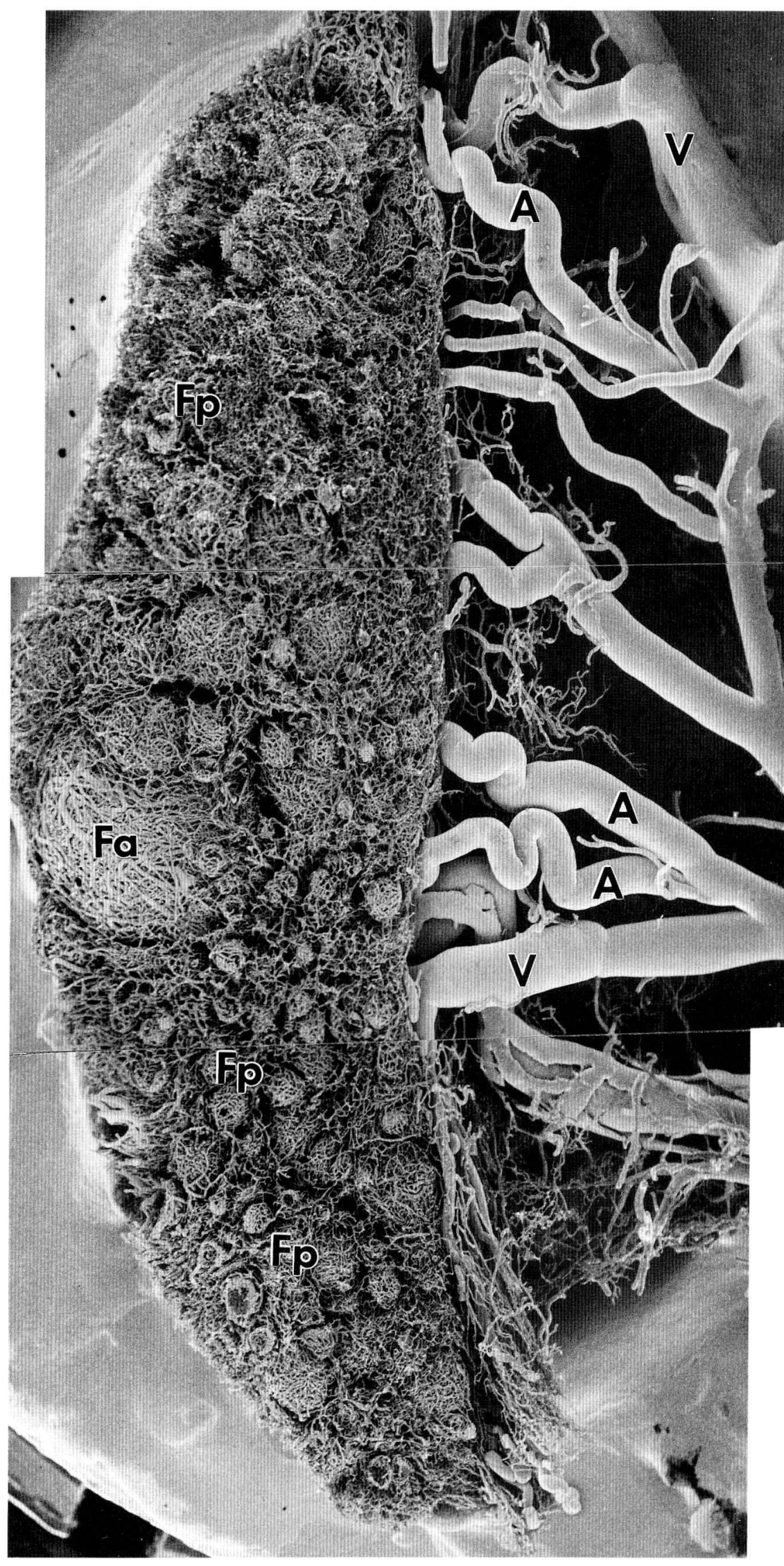

Fig. 1. View of the surface of a vascular corrosion cast of the rabbit ovary. Spiral arteries $(A)$ and veins $(V)$ are seen at the hilus. Numerous vascular plexuses of follicle of varying size are present. $F p$ pre-antral follicles, $F a$ antral follicles. $\times 20$ 
tioning endocrine tissue (GREENWALD and TERRANOVA, 1988). Surprisingly, the microvascular changes accompanying these processes remained to be fully studied by SEM of vascular corrosion casts (KIKUTA et al., 1991), a technique which may actually provide the best visualization of the morphology of the microvascular patterns and of changes in both physiological and pathological conditions (MURAKAMI, 1971).

Therefore, in order to provide a morphological comparison of the microvasculature of the theca layer of evolutive and atretic follicles, we employed SEM in our study of rabbit ovary vascular corrosion casts.

\section{MATERIALS AND METHODS}

Animals: Eight normal, white, New Zealand rabbits were used for casting. In addition, two animals were not casted and used as controls. All animals were adult virgin females weighing $4-5 \mathrm{~kg}$, and were caged separately for at least 21 days prior to ovarian sampling.

Vascular casts: After anesthesia, induced by intravenous Nembutal injection in the external ear vein, the animals were subjected to laparotomy and median sternotomy. The thoracic aorta was cannulated and a saline solution $\left(\mathrm{RT}^{\circ}\right)$ was injected slowly. After washing out the blood, a Mercox resin was slowly injected into the animals until polymerization started. The ovaries were then removed and placed in warm water for 3-4 h until polymerization was completed. The samples underwent maceration in a $10 \% \mathrm{NaOH}$ solution for $24-48 \mathrm{~h}$ at $60^{\circ} \mathrm{C}$. After maceration was completed, samples were washed under running tap water for two hours and then kept in distilled water for 2-3 days at $60^{\circ} \mathrm{C}$ to remove residual tissue. Ovarian vascular casts were carefully exposed under stereo microscopic magnification, air dried, mounted on aluminum stubs with a conductive paste and sputtered with gold (MURAKAMI et al., 1988; MACCHIARELLI et al., 1991).

Controls: Ovaries from uncasted control animals were processed for light microscopy observations (CHERNEY et al., 1975).

Observations: SEM observations were performed with Hitachi field emission S-4000, Hitachi S-2R and

Fig. 2. View of a freeze-fractured vascular cast of the rabbit ovary. Medulla $(M)$ and cortex $(C)$ are seen. Medullary vessels $(\rightarrow)$ and their cortical branches supplying the follicle vascular plexuses are exposed. $F p$ preantral follicles, $\mathrm{Fa}$ antral follicles. $\times 20$

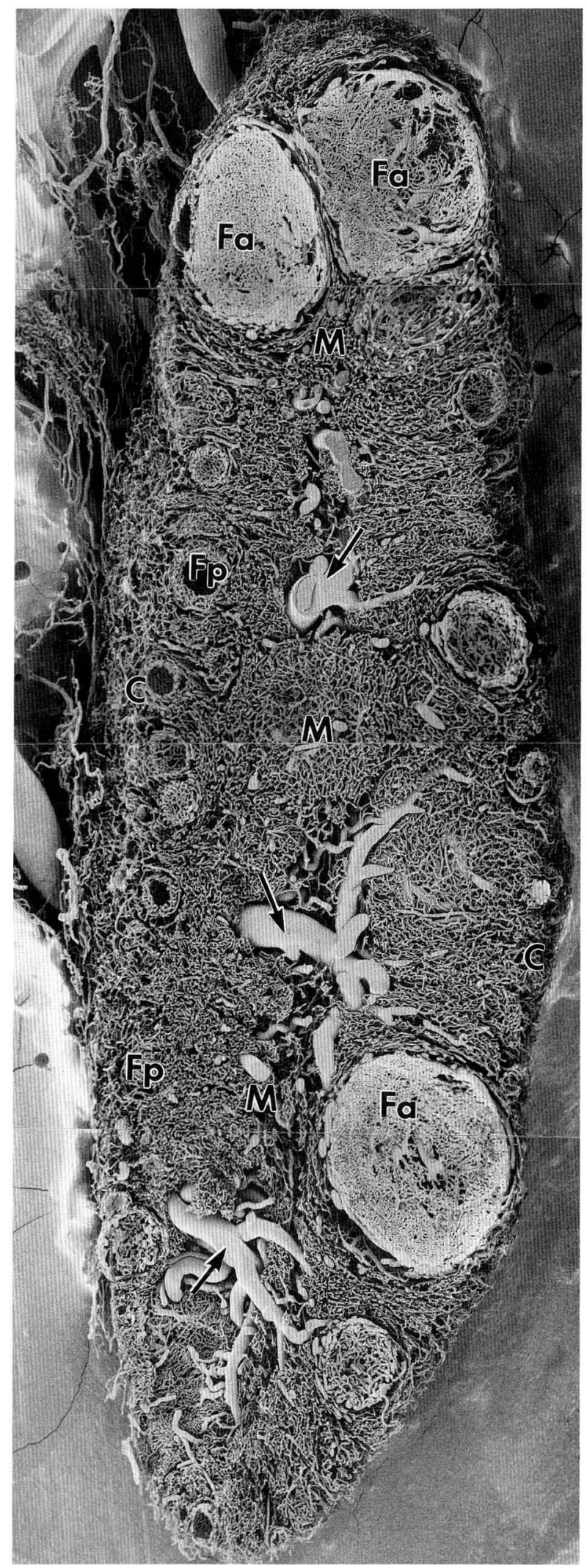




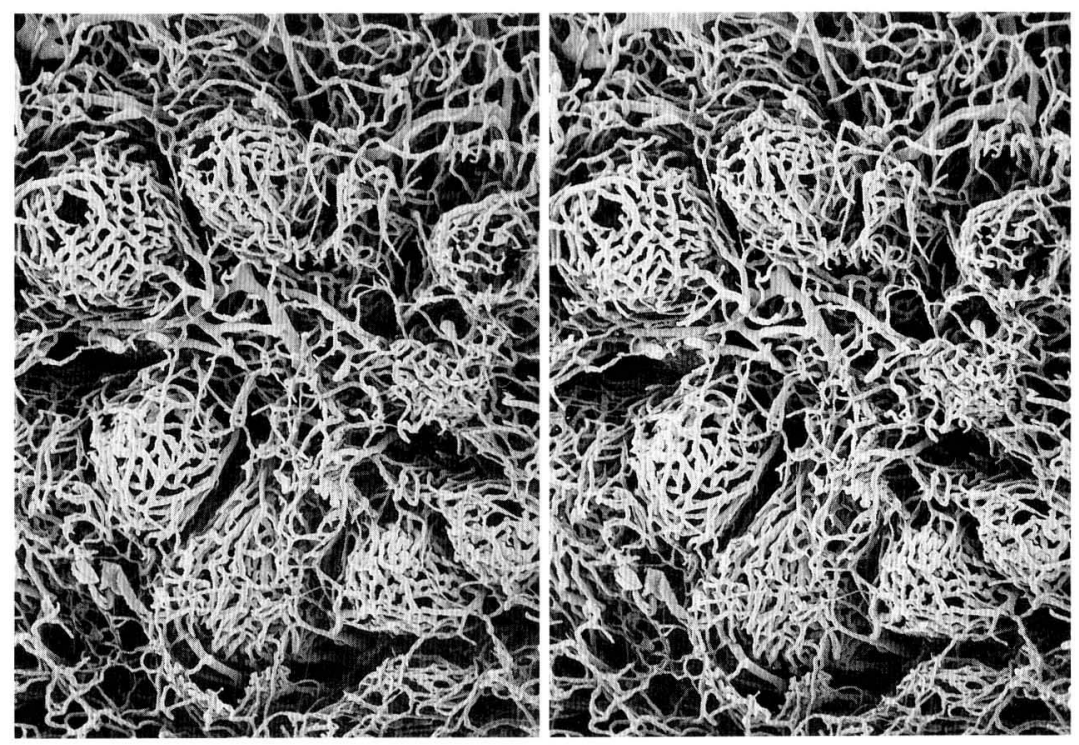

Fig. 3. Stereo pair of cortical vascular plexuses. Several small round plexuses show a common arteriolar and venular supply. $\times 60$

Jeol SM-U3 scanning electron microscopes, operating at $4-7 \mathrm{kV}$.

\section{RESULTS}

\section{Controls}

Light microscopy of uncasted control ovaries displayed numerous follicles located mainly in the cortical areas. Primordial, primary, secondary, and cavitary follicles were found. Most of these had a normal appearance, however, several follicles presented morphological signs of involution (atresia) in the oocyte, and/or granulosa and/or theca. Neither ovulatory follicles or corpora lutea could be detected.

\section{General aspects of casted ovaries}

The surface of the vascular corrosion casts revealed numerous regularly or irregularly rounded structures located within the ovarian cortex, these structures being the vascular plexuses of the theca layers of various types of follicles. The vascular plexuses varied in size, having diameters from 80 to $1000 \mu \mathrm{m}$ (Fig. 1). In fractured ovaries, these plexuses were confined mainly to the external part of the cortical area, though the largest follicles reached also the deepest layer of the cortex (Fig. 2).

Larger vascular plexuses were isolated by the vasculature of the surrounding interstitial tissue. Smaller vascular plexuses showed numerous capillary anastomoses with the interstitial tissue vessels (Fig. 3).

Most vascular plexuses were supplied by one or two small arterioles that originated from the cortical arteries (Fig. 4A). Sometimes the same cortical artery supplied two smaller arteries of different vascular plexuses (Fig. 3). The venous drainage of vascular plexuses comprised several short thick venules connected to a longer and thicker vessel (Fig. 4B). The latter was collected by extra follicular cortical vessels that emptied into the medullar veins (Fig. 2).

In fractured samples, the regularly rounded vascular plexuses usually showed a basket-like configuration (Figs. 4-5). These presented a central avascular area (Fig. 4A) corresponding to the zones that were occupied by the granulosa layer, the oocyte and its investment, and the antral cavity before corrosion. These irregularly rounded vascular plexuses were either completely devoid of the central avascular area (Fig. 6) or presented sprouts of vascular growth which partially occupied the centrum of the baskets (Fig. 7A).

Fig. 4. Type 1 vascular plexuses. A. In a fractured sample note the monolayered wall and the central avascular cavity. B. The outer surface of the microvasculature of a preantral follicle. Several thin capillaries are drained by thicker venules. $\times 320$ 

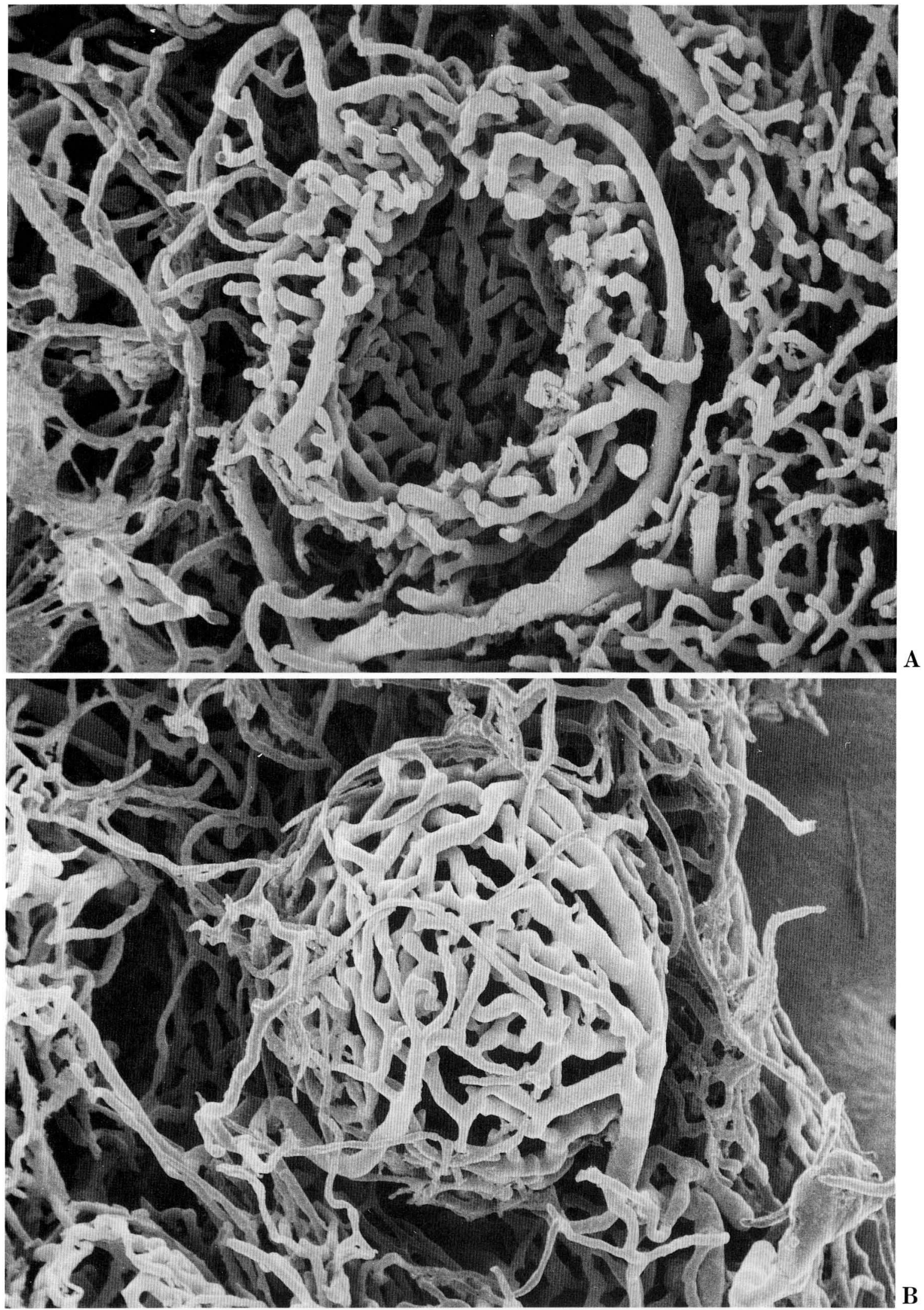

Fig. 4. Legend on the opposite page. 


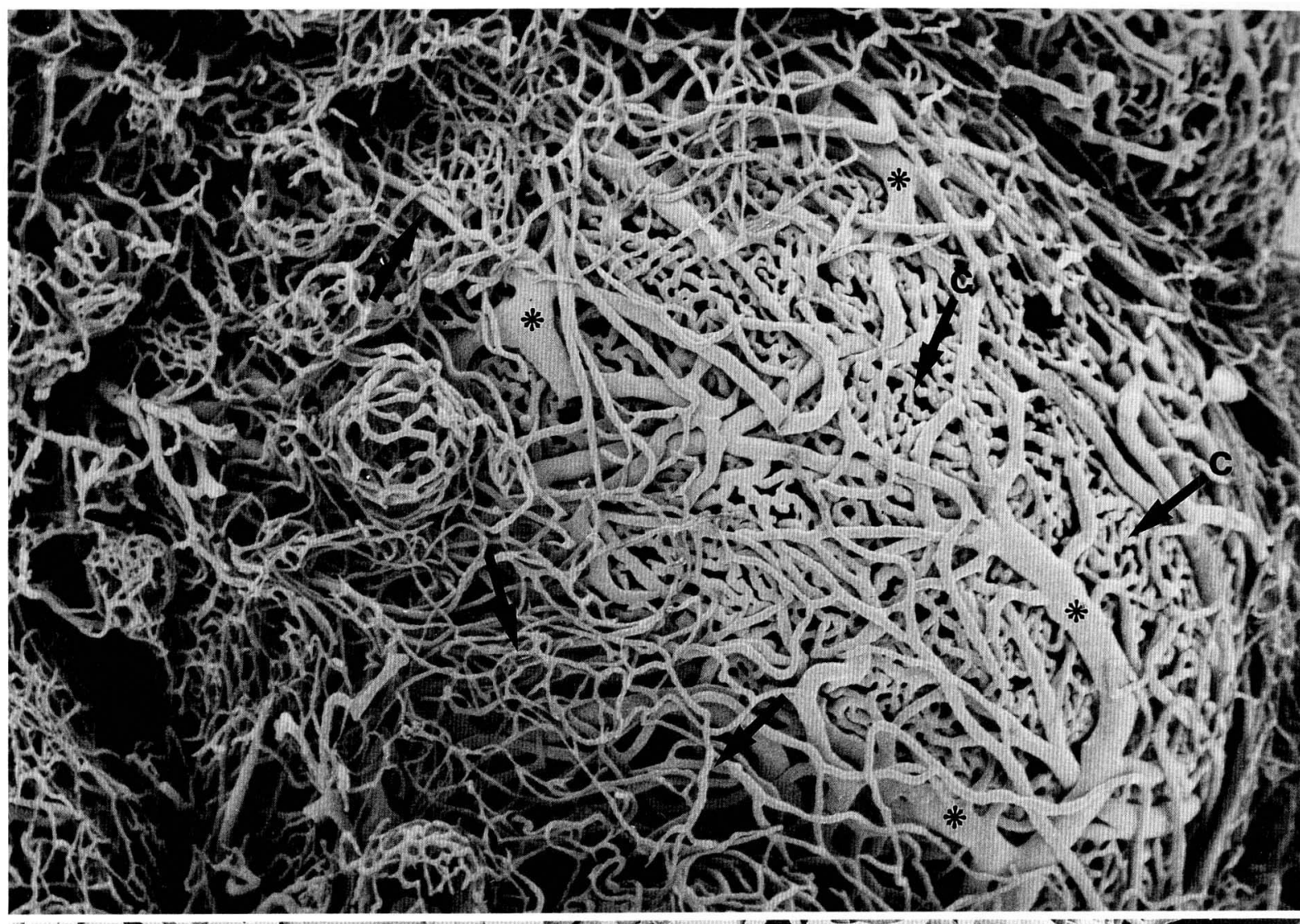

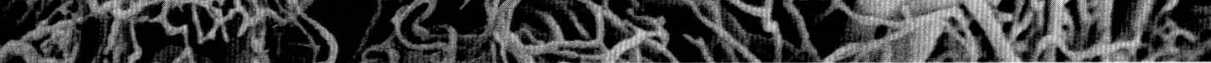

i.

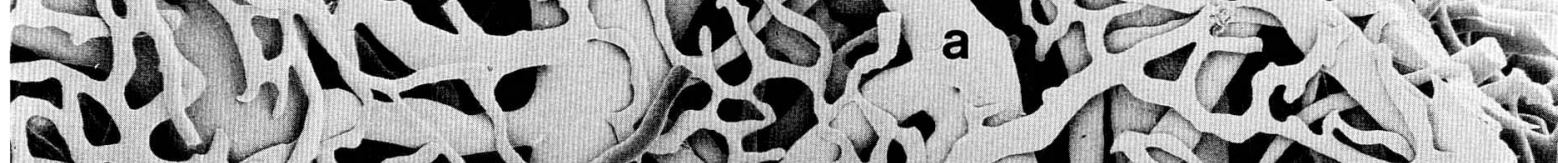

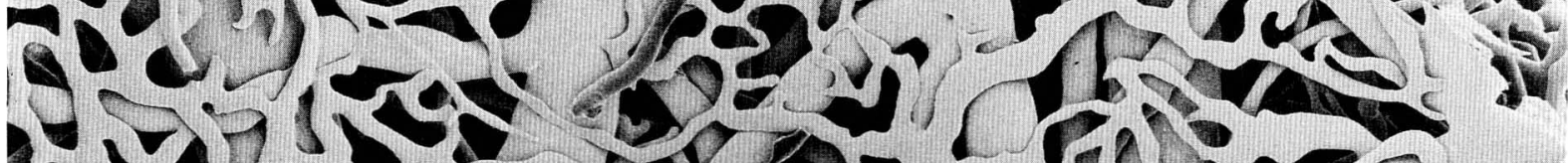

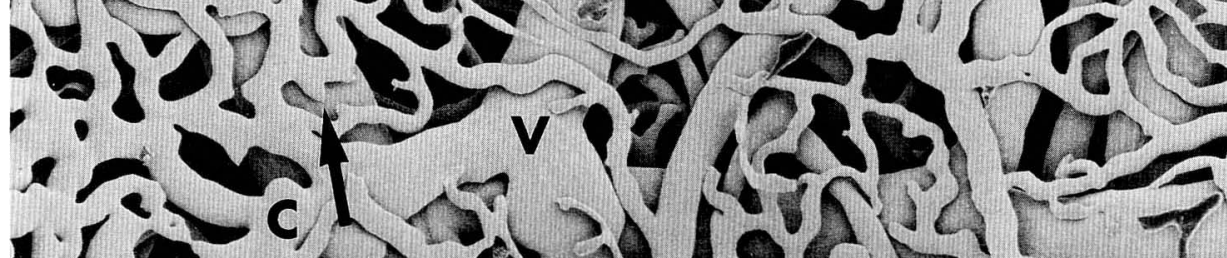

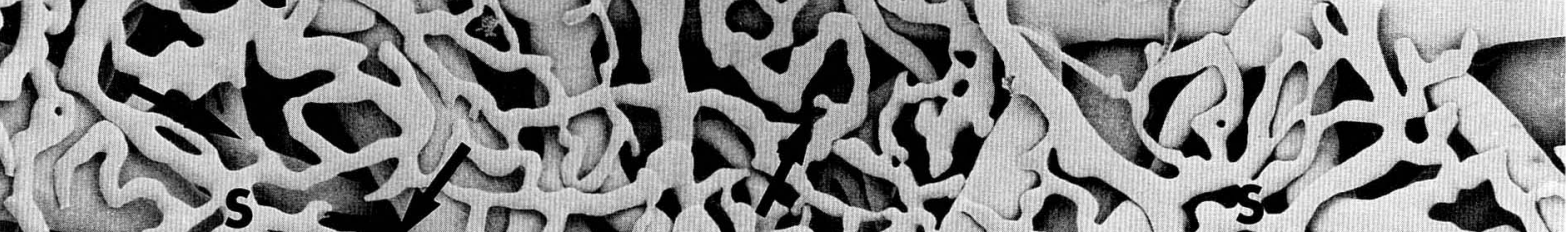

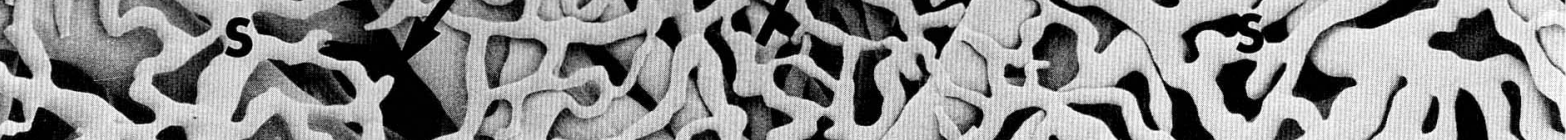

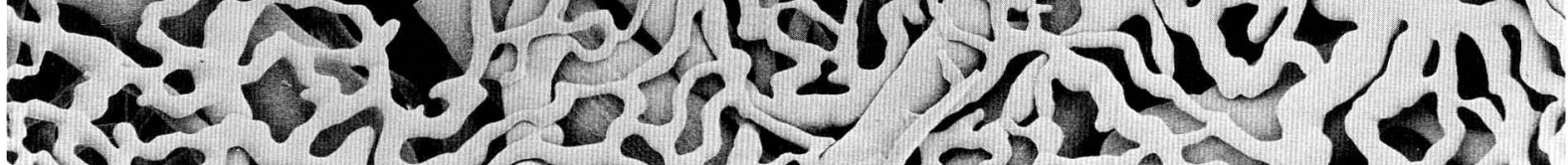
$\because$ a

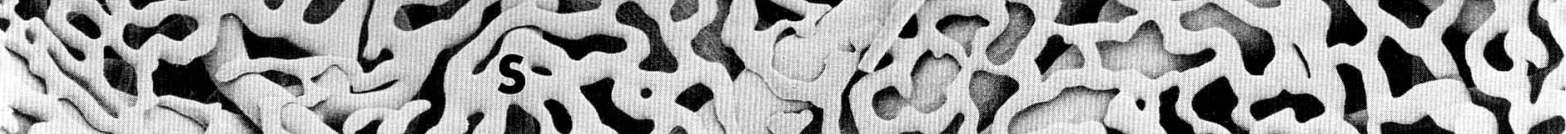
B $7 .>$.

Fig. 5. Legend on the opposite page. 


\section{Microvasculature of the follicles}

Four different types of vascular plexuses were recognized according to the size and characteristics of their capillaries.

Type 1 (Figs. 3-4): These were rounded vascular plexuses, $100-250 \mu \mathrm{m}$ in diameter (Fig. 4A), consisting of a monolayer of capillaries that surrounded a central empty avascular area (Fig. 4B). The capillary vessels were usually thin $(4-5 \mu \mathrm{m}$ in diameter) and arranged in a large polygonal-meshed network.

Type 2 (Fig. 5): These were regularly rounded or ovoid plexuses with a diameter greater than $250 \mu \mathrm{m}$, and were characterized by an inner layer of uniformly distributed capillaries. These plexuses were highly variable in size, and could even reach $1000 \mu \mathrm{m}$ in diameter. In fractured samples, they always showed a large empty cavity, displaying a basket-like configuration. The walls of these baskets consisted of three layers of vessels (Fig. 5A): 1) an outer layer, made of thin $(4-5 \mu \mathrm{m}$ in diameter) capillaries, forming a coarse plexus; 2) a medial layer, made of intermingled thick vessels which, according to the size and surface morphology of the nuclear prints, corresponded to arterioles and venules; and 3) an inner layer, made of capillaries uniformly distributed to delimit the central cavity. The inner layer showed morphological differences in relation to the size of the vascular plexuses. In fact, these capillaries gradually increased in thickness (ranging 6-10 $\mu \mathrm{m}$ in diameter) and tortuousity, together with the enlargement of the plexus. Particularly, the inner capillaries in the largest plexuses (Fig. 5B) were arranged in a sinusoidal net with rounded meshes. In addition, these capillaries showed interruptions characterized by thin endings.

Type 3 (Fig. 6): These were irregularly rounded (Fig. 6A) or ovoid (Fig. 6B) plexuses with diameters of $80-250 \mu \mathrm{m}$. They were characterized by a coarse capillary plexus which also invaded the central antral cavity, as better evidenced in fractured samples (Fig. $6 \mathrm{C})$. The capillaries were thin and arranged in a polygonal-meshed network.

Type 4 (Fig. 7): These were plexuses with diameters greater than $250 \mu \mathrm{m}$, characterized by the presence of thin (4-5 $\mu \mathrm{m}$ in diameter) and thick (6-12 $\mu \mathrm{m}$ in diameter) capillaries in the inner layer. These plexuses displayed a multilayered wall similar to that of Type 2, with the exception of the inner capillary layer which showed remarkable differences (Fig. 7A). Inner capillaries were not uniformly distributed as in Type 2 plexuses, but varied in size and arrangement. In some areas the capillaries were thin, but tortuous and dilated in others (Fig. 7B). In some plexuses, the inner capillaries were abnormally dilated and thick (Fig. 7C). The largest plexuses showed both avascular lacunae within the sinusoidal net, and the central cavity was focally invaded by a coarse capillary net. These invading capillaries were supplied by underlying thicker vessels resembling arterioles and venules, and were connected with the vessels of the medial layer of the plexus wall (Fig. 7A).

\section{DISCUSSION}

In the present work, SEM of vascular corrosion casts of the rabbit ovary allowed visualization of the blood vessels supplying the follicular theca layer. As previously shown (KANZAKI et al., 1982; MURAKAMI et al., 1988; KIKUTA et al., 1984, 1991; MACCHIARELLI et al., 1992a, b) the theca microvasculature of follicles in this study also appeared to be primarily arranged in typical structures, usually called vascular plexuses, vascular baskets or vascular wreaths.

In the casted ovaries, four main types of vascular plexuses were found and classified according to their diameters and characteristics of their capillaries. In particular we observed two kinds of vascular plexuses (Types 1 and 2) showing general features of the vascular casts of the theca of evolutive follicles (MACCHIARELli et al., 1992a, b). Furthermore, this study revealed two other kinds of follicular vascular plexuses (Types 3 and 4) that presented morphologies significantly different from the previous ones.

\section{The follicular vascular plexuses}

Earlier studies by SEM of vascular corrosion casts of the mammalian ovary identified three main types of vascular plexuses (MURAKAMI et al., 1988; MACCHIARELLI et al., 1992b). First, regularly round vascular plexuses, surrounding a central avascular area, with a diameter ranging from $80-1000 \mu \mathrm{m}$. These displayed a

Fig. 5. Type 2 vascular plexuses. A. Outer surface of the vascular plexus of an antral follicle. The outer coarse network of thin capillaries (arrows), the medial layer of thicker vessels $(*)$, and the inner capillary network $(c \rightarrow)$ are seen. $\times 80$. B. Inner view of the capillary network. Note sinusoids $(S)$ arranged in a round-meshed network supplied by underlying arterioles $(a)$ and drained by underlying collecting capillaries $(C)$ and venules $(V)$. Thin interruptions (arrows) are mainly related to angiogenic sprouts. $\times 220$ 


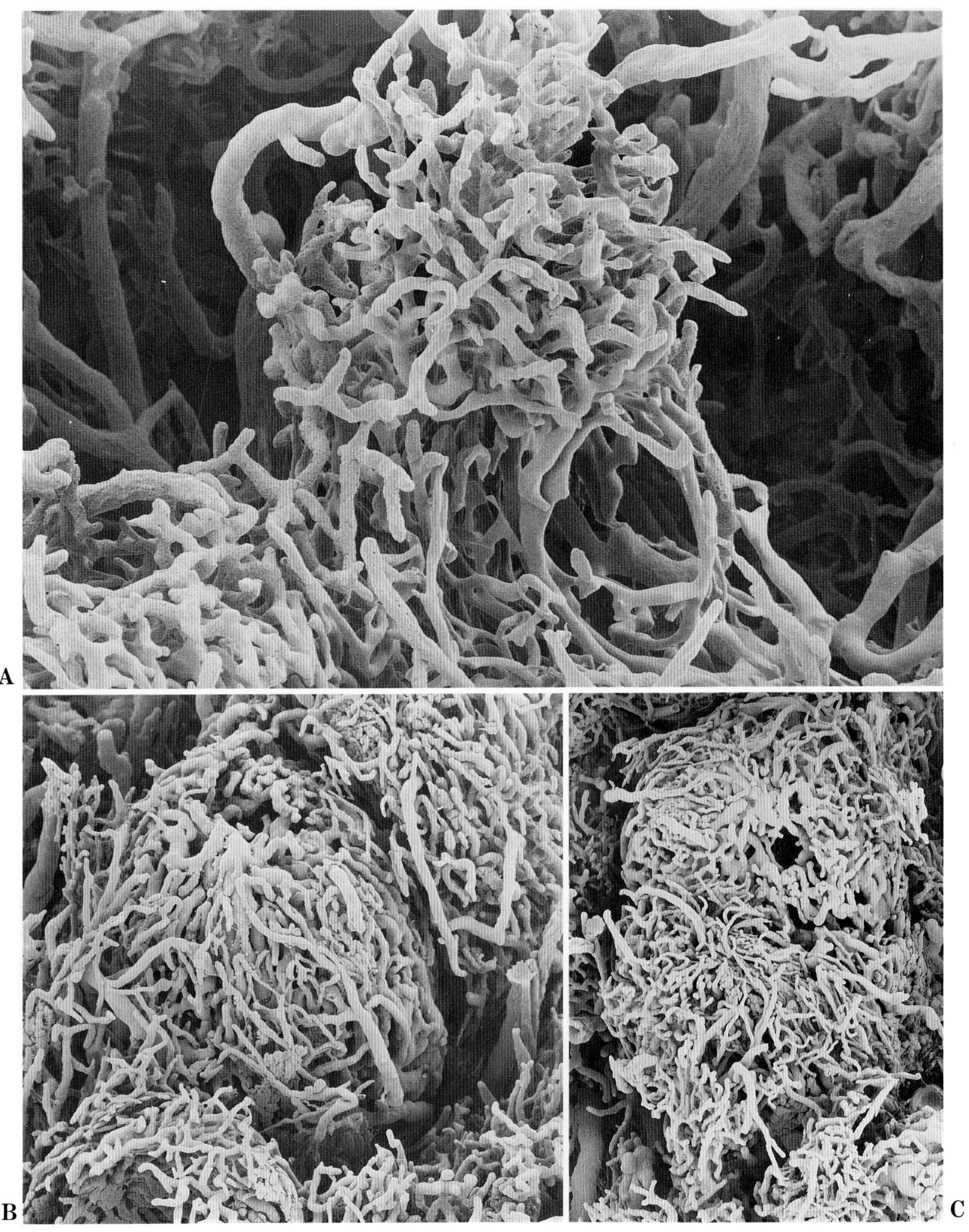

Fig. 6. Type 3 vascular plexuses. A. Irregular shaped vascular plexus, well isolated from the surrounding structures and presenting thin capillaries randomly arranged. $\times 270$. B. Outer surface of an ovoid vascular plexus made of thin capillaries. $\times 120$. C. Fractured irregularly shaped vascular plexus, made of thin capillaries invading the central area. $\times 80$ 
gradual increase in wall thickness, and the development of the inner vascular layer from a polygonalmeshed network of thin capillaries (smallest baskets) to a rounded-meshed network of thick sinusoids (largest baskets). These plexuses appeared to correspond to growing follicles in the evolutive phase, from primary to preovulatory stages (KARDON and KESSEL, 1979; KANZAKI et al., 1982; KIKUTA et al., 1984, 1991; MURAKAMI et al., 1988; MACCHIARELli et al., 1991, 1992a, b). Second, regularly round or ovoid vascular baskets of large diameter, present only during spontaneous or stimulated ovulatory phases. These showed a large central avascular area, a thick multilayered wall (often interrupted by the stigma), and an inner layer formed of a rounded meshed net of sinusoids often presenting blebs of resin leakage (the latter a sign of capillary permeabilization). These plexuses were considered to be characteristic of follicles ready for ovulation (KANZAKI et al., 1982; KITAI et al., 1985; MURAKAMI et al., 1988; OKAMURA, 1989; MACCHIARELLI et al., 1992b). Third, irregularly round or more often ovoid vascular plexuses, sometimes collapsed, characterized by an exuberant invasion of thick capillaries in the central avascular area and corresponding to corpora lutea. In particular, dense and highly capillarized plexuses were considered to be growing corpora lutea, whereas collapsed and less vascularized plexuses were identified as regressing corpora lutea (MURAKAmi et al., 1988; KiKUTA et al., 1991; MACCHIARELLI et al., 1992b).

In our study we used normal, virgin adult rabbits, not subjected to any natural (mating) or pharmacological (hCG intravenous injection) stimulation. Thus, since the rabbit is a reflexed ovulator, the ovaries only possessed follicles in various developing stages, from primary to cavitary (CHERNEY et al., 1975), as was also confirmed by the light microscopy observations of control uncasted rabbits. Therefore, the vascular baskets in these ovaries could not correspond to either the theca of ovulatory follicles or to the microvasculature of corpora lutea.

According to the above studies on ovarian vascular casts and to electron microscopic data on unstimulated rabbit ovaries (CHERNEY et al., 1975), Types 1 and 2 vascular plexuses correspond to the theca microvasculature of evolutive follicles. In particular, Type 1 was reported to supply primary or early secondary follicles, and Type 2, early-late antral follicles (MACCHIARELLI et al., 1991, 1992b).

Types 3 and 4 vascular plexuses were not previously described, and corresponded to atretic follicles.

\section{The follicular atresia}

Follicular atresia is a widely occurring phenomenon, seen in most vertebrates, including humans, in which 99\% of the follicles are involved (BYSKOV, 1978). Morphological changes in the structure or environment of the follicles may result in disturbances of follicle maturation, usually followed by its rapid involution (GREENWALD and TERRANOVA, 1988). This may occur at any stage of follicular development (HUBBARD and OXBERRY, 1991). The morphofunctional development of the atretic process may have different aspects according to species or physiopathological condition (BYSKOV, 1978). In the early stages of follicular growth, atresia primarily involves the oocyte, whereas in further follicular developmental stages, granulosa and theca layers are dramatically affected by this process (FAMILIARI et al., 1991; HUBBARD and OXBERRY, 1991).

In the rabbit, as shown by histochemical studies (GURAYA and GREENWALD, 1964a), the growing follicles present two forms of atresia that may strike follicles at any stage of development: 1) Degenerative atresia, which ends in a regression of the follicular structures and an obliteration of the follicle; 2) Luteinizing atresia, which is morphologically characterized by thecal hypertrophy. According to our data, the Type 3 vascular plexuses supply follicles in the degenerative type of atresia, whereas Type 4 vascular plexuses supply follicles in the luteinizing type of atresia. In fact, Type 3 plexuses were devoid of a central cavity, being invaded by thin capillaries related to the inflammatory process occurring during the follicle regression (BYSKOV, 1978). In addition, Type 4 plexuses showed tortuous and thick capillaries, resembling sinusoids, that characteristically supply ovarian structures with endocrine activity (GREENWALD and TERRANOVA, 1988; MACCHIARELLI et al., 1992b). This further evidences the presence, in the rabbit, of an endocrinally active "interstitial gland" that is known to be mainly sustained by luteinized theca cells of atretic follicles (GURAYA and GREENWALD 1964a, b; HUBBARD and OXBERRY, 1991). An indirect proof of this is the fact that, in the sheep with its poor level of endocrine activity for the interstitial gland, atretic follicles show a deficient theca layer and a reduction of the capillary network (HAY et al., 1976; O'SHEA et al., 1978; FINDLAY and CARSON, 1980). The areas of thin capillaries invading the central cavity seen in Type 4 plexuses represent the onset of regression which, in general, is the fate of all these atretic follicles (HUBBARD and OXBERRY, 1991). 


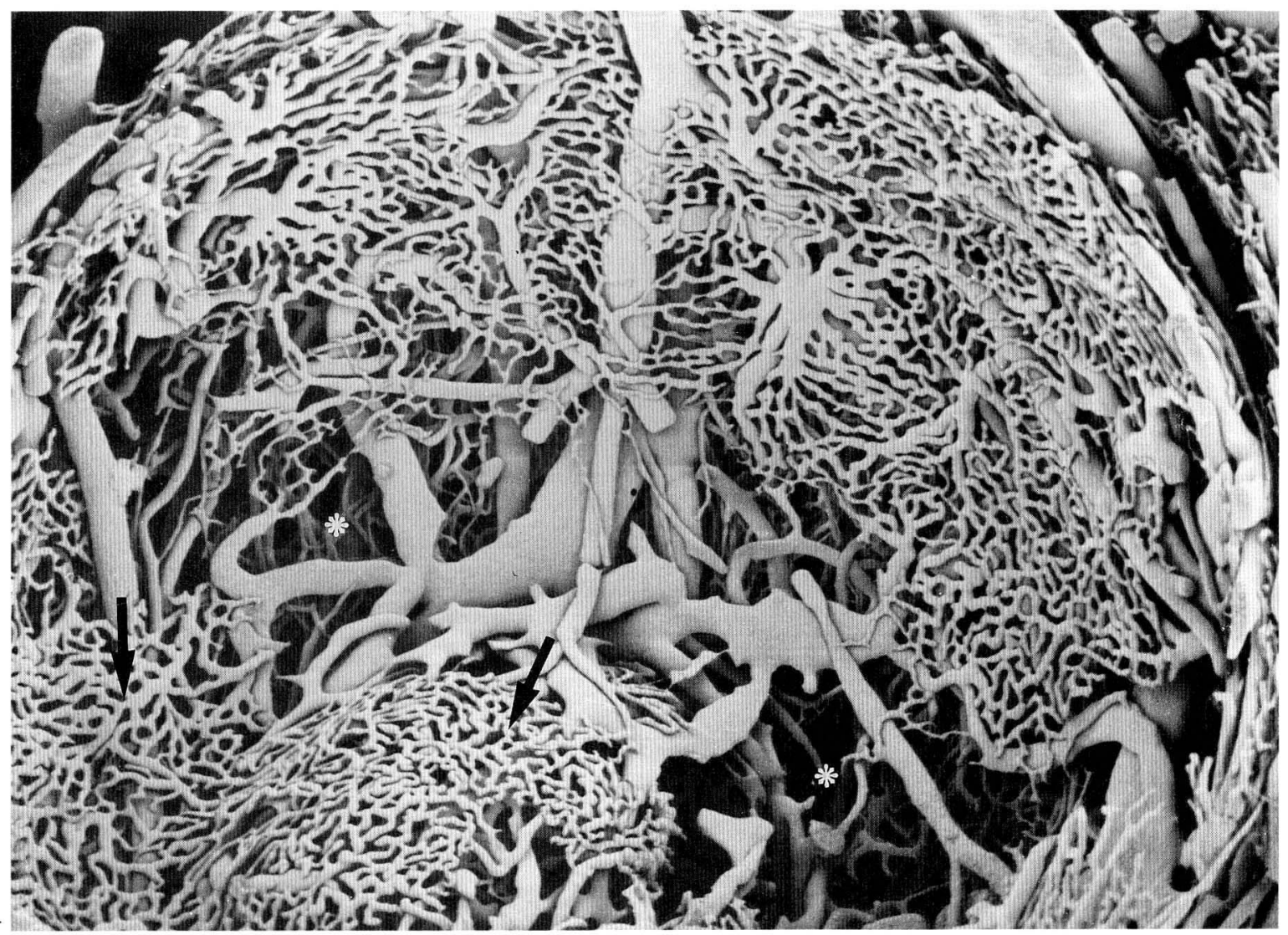

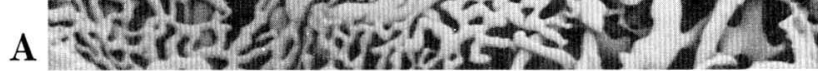

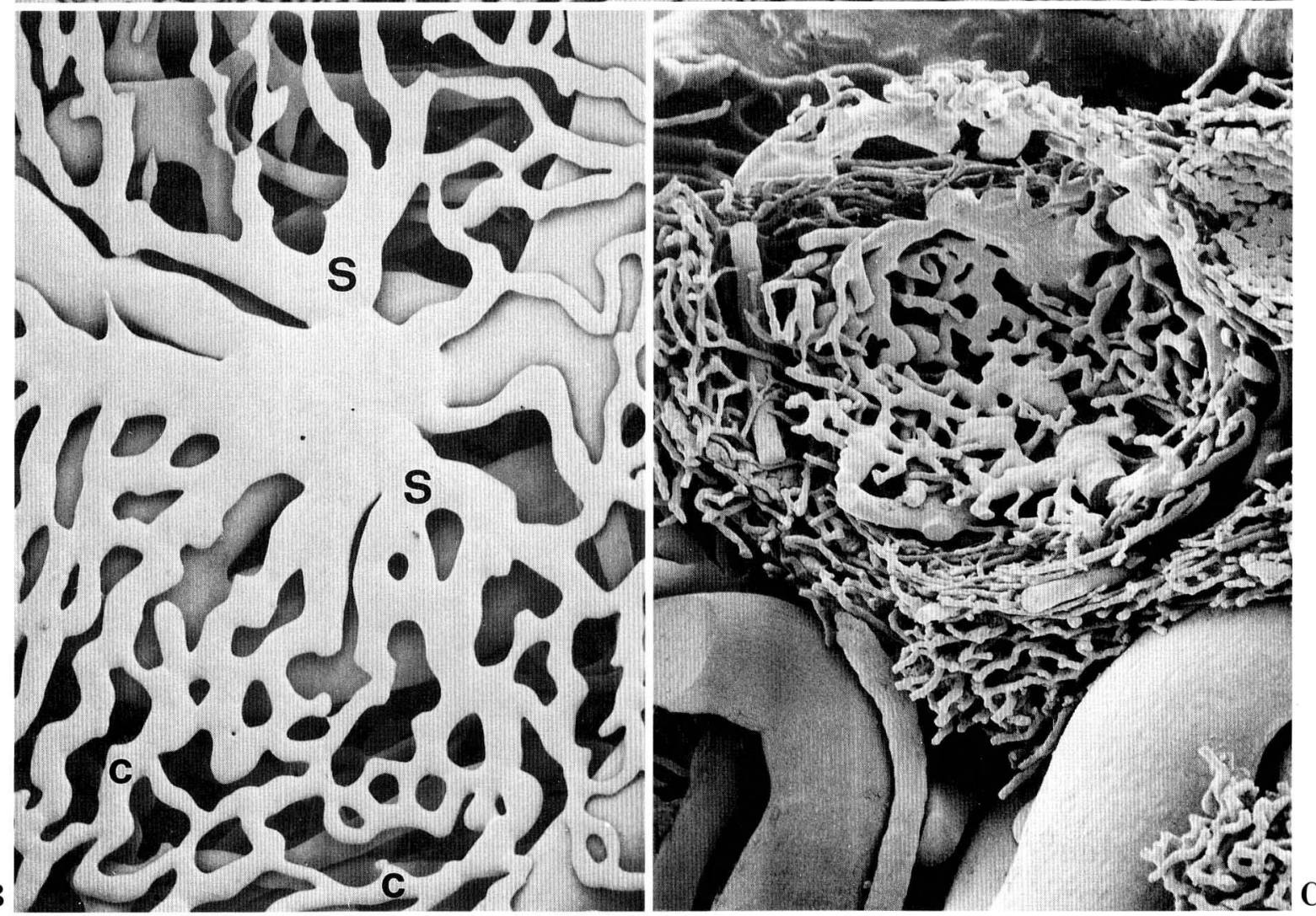

Fig. 7. Legend on the opposite page. 


\section{The follicular hemodynamics}

Follicular growth requires an increase in the intraovarian blood flow which likely is related to four factors (REYNOLDS, 1973; GREENWALD and TERRANOVA 1988; MACCHIARELLI et al., 1992b): 1) intraovarian growth of new vessels (angiogenesis); 2) vasodilatation of existing capillaries; 3 ) change in spiralization of hilar vessels; 4) increase in the blood flow to the ovary from the systemic circulation. While the latter may be only demonstrated by a physiological approach, the first three points may be sustained by morphological data. In particular, our data on the vascular casts of growing follicles (Type 1, 2 vascular plexuses) clearly showed that both angiogenesis and dilatation of existing capillaries were present. Considering the data reported here on unstimulated rabbits, we cannot exclude the possibility that hilar vessels may undergo dilatation or even change their spiralization pattern when ovulation is imminent, as has also been revealed by previous studies (REYNOLDS, 1973). However, our preliminary SEM observations on vascular casts of stimulated rabbit ovaries (NOTTOLA et al., 1991) were not fully consistent with this view. In fact, intraovarian juxta-medullary blood vessels were not greatly affected by hCG stimulation. The changes previously described by means of other techniques, and which consisted in an extension of the arterial spirals after hCG injection in rabbits (REYNOLDS, 1973), probably regarded only the extra-ovarian ramifications of the utero-ovarian arcade (NOTTOLA et al., 1991).

Microvascular changes such as a local follicular ischemia, have been considered among the etiological causes of atresia (GREENWALD and TERRANOVA, 1988; HUBBARD and OXBERRY, 1991). Although our data clearly confirm the occurrence of significant vascular changes in both luteinizing and obliterant atresia in the rabbit, they do not support the "ischemic" theory. In Type 3, 4 vascular plexuses, the changes we observed were primarily characterized by an invasion of the follicular cavity as typically seen during inflammatory reaction. The inflammatory stimulus for atresia has been suggested to be induced by changes in the permeability of the follicular basal membrane (FAROOKHI, 1981). The vascular changes seen in preovulatory follicles have also been understood as an inflammatory event (ESPEY, 1980). Therefore, we be- lieve that the changes we observed represent a consequence of the degenerative process, rather than an active cause of atresia (GREENWALD and TERRANOVA, 1988).

\section{REFERENCES}

Byskov, A. G: Follicular atresia. In: (ed. by) R. E. Jones: The vertebrate ovary. Plenum Press. New York-London, 1978 (p. 533-562).

Cherney, D. D., L. J. A. DiDio and P. M. Motta: The development of rabbit ovarian follicles following copulation. Fertil. Steril. 26: 257-270 (1975).

EsPEY, L. L.: Ovulation as an inflammatory reaction. A hypothesis. Biol. Reprod. 22: 73-106 (1980).

Familiari, G., E. Vizza, A. Miani and P. M. Motta: Ultrastructural and functional development of the theca interna. In: (ed. by) G. FAMILIARI, S. MAKABE and P. M. MotTA: Ultrastructure of the ovary. Kluwer Academic Publishers, Boston-Dordrecht, 1991 (p. 113-128).

FArookнi, R: Atresia, an hypothesis. In: (ed. by) N. B. Schwartz and M. HunzKen Dumm: Dynamics of ovarian function. Raven Press, New York, 1981 (p. 13-23).

Findlay, J. K. and R. S. Carson: Selective bindings of gonadotrophins and the control of follicular growth and atresia. In: (ed. by) B. Flerko, G. Setalo and L. Tima: Advance in physiological science: Reproduction and development. Pergamon, Budapest, 1980 (p. 79-89).

Greenwald, G. S. and P. F. Terranova: Follicular selection and its control. In: (ed. by) E. KNOBIL, J. NeILL, et al.: The physiology of reproduction. Raven Press Ltd, New York 1988 (p. 387-445).

Guraya, S. S. and G. S. Greenwald: Histochemical studies on the interstitial gland in the rabbit ovary. Amer. J. Anat. 114: 495-520 (1964a).

- : A comparative histochemical study of interstitial tissue and follicular atresia in the mammalian ovary. Anat. Rec. 149: 411-434 (1964b).

HaY, M. F., D. G. GraN and R. R. Moor: Structural changes occurring during atresia in sheep ovarian follicles. Cell Tiss. Res. 169: 515-529 (1976).

HeEs, H., H. E. KöNig and I. HeEs: Recherches sur la structure vasculaire du systeme de vaisseaux sanguins des structures elaborees au cours du cycle ovarien chez la jument. Une recherche au microscope optique et au microscope electronique a balayage. Contracept. Fertil. Sex. 16: 521-526 (1988).

Hubbard, C. J. and B. Oxberry: Follicular atresia. In: (ed. by) G. Familiari, S. Makabe and P. M. Motta: Ultrastructure of the ovary. Kluwer Academic Publishers, Boston-Dordrecht, 1991 (p. 273-285).

Fig. 7. Type 4 vascular plexuses. A. large, round fractured vascular plexus showing an inner wall made of differently arranged capillaries. Note avascular areas in the inner wall $(*)$ and capillaries invading the central cavity (arrows). $\times 300$. B. Higher magnification of Fig. 7A; note the occurrence of sinusoids $(S)$ and thinner capillaries $(c)$. C. A round fractured vascular plexus showing very dilated inner vessels. $\times 150$ 
Kanzaki, H., H. OKamura, Y. OKuda, A. Takenaka, K. Morimoto and T. Nishimura: Scanning electron microscopic study of rabbit ovarian follicle microvasculature using resin injection-corrosion casts. J. Anat. 134: 697704 (1982).

KARDon, R. H. and R. G. Kessel: SEM studies on vascular casts of the rat ovary. Scanning Electron Microsc. 1979 /III: 743-750 (1979).

Kikuta, A., G. Macchiarelli and T. Murakami: Microvasculature of the ovary. In: (ed. by) G. FAMILIARI, S. MAKABE and P. M. MotTA: Ultrastructure of the ovary. Kluwer Academic Publishers, Boston-Dordrecht, 1991 (p. 239-254).

Kikuta, A., A. Ohtsuka, O. Ohtani and T. Murakami: Microvascularization of endocrine glands as studied by injection-replica SEM method. In: (ed. by) P. M. MoTTA: Ultrastructure of endocrine cells and tissues. Martinus Nijhoff Publishers, Boston, 1984 (p. 314-320).

Kitai, H., Y. Yoshimura, K. H. Write, R. SANtulli and E. E. WALlACH: Microvasculature of preovulatory follicles: comparison of in situ and in vitro perfused rabbit ovaries following stimulation of ovulation. Amer. J. Obstet. Gynecol. 152: 889-895 (1985).

Köning, H. E., W. AMSELGRUBER and I. RUSSE: La microcirculation dans les follicles et les corps jaunes d'ovaires de bovins. Une etude anatomique par corrosion. Contracept. Fertil. Sex. 17: 179-186 (1989).

Macchiarelli, G., S. A. Nottola, E. Vizza, A. Kikuta, T. Murakami and P. M. Motta: Ovarian microvasculature in normal and hCG stimulated rabbits. A study of vascular corrosion casts with particular regard to the interstitium. J. Submicrosc. Cytol. Pathol. 23: 391395 (1991).

Macchiarelli, G., E. Vizza, S. A. Nottola, G. Familiari and P. M. MotTA: Cellular and microvascular changes of the ovarian follicle during folliculogenesis: A scanning electron microscopic study. Arch. Histol. Cytol. 55, Suppl.: 191-204 (1992a).

Macchiarelli, G., S. A. Nottola, A. Kikuta, O. Ohtani, T. Murakami and P. M. Motta: The ovary: threedimensional morphodynamics of the luteofollicular complex by SEM of vascular corrosion casts and other EM techniques. In: (ed. by) P. M. MotTA, T. Murakami and H. FUJITA: Scanning electron microscopy of vascular casts: methods and applications. Kluwer Academic Publishers, Boston-Dordrecht, 1992b (p. 245-259).

MotTa, P. M., S. A. NotTola, G. FAmiliari, G. MACChiaReldi and E. Vizza: Follicular structures: An ultrastructual study by scanning and transmission electron microscopy and correlated techniques. In: (ed. by) N. O. SJÖBERG, L. Hamberger, P. O. Janson, Ch. OWman and H. J. T. COELING-BENNIK: Local regulation of ovarian function. The Partenon Publishing Group, Carnforth-Lancs, 1992 (p. 39-53).

MotTa, P. M. and J. VAN BLerkom: A scanning electron microscopy study of the luteo-follicular complex. I. Follicle and oocyte. J. Submicrosc. Cytol. 6: 297-310 (1974).
-: A scanning electron microscopy study of the luteo-follicular complex. II. Events leading to ovulation. Amer. J. Anat. 143: 241-264 (1975).

Murakami, T: Application of the scanning electron microscope to the study of fine distribution of the blood vessels. Arch. Histol. Jap. 32: 445-454 (1971).

Murakami, T., Y. IKebUChi, A. Ohtsuka, A. Kikuta, T. TAGUCHI and O. OHTANI: The blood vascular wreath of rat ovarian follicle, with special reference to its changes in ovulation and luteinization: a scanning electron microscopic study of corrosion casts. Arch. Histol. Cytol. 51: 299-313 (1988).

Murdoch, W. J. and J. L. CAVEnder: Effect of indomethacin on the vascular architecture of preovulatory ovine follicles: possible implication in the luteinized unruptured follicle syndrome. Fertil. Steril. 51: 153-155 (1989).

Nottola, S. A., G. Macchiarelli, E. Vizza, G. Familiari, M. Napoli and P. M. MotTa: Hilar vessels of the ovary as seen by scanning electron microscopy of vascular corrosion casts. Microsc. Electron. 2, Suppl.: 77-78 (1991).

OKamura, T.: Morphological observation on ovulation. In: (ed. by) P. M. MotTA: Developments in ultrastructure of reproduction. Alan R. Liss, Inc., New York, 1989 (p. 79-90).

O'Shea, J. D., M. F. HAY and D. G. AAU: Ultrastructural changes in theca interna during follicular atresia in sheep. J. Reprod. Fertil. 54: 183-187 (1978).

REYNolds, S. R. M.: Blood and lymph vascular systems of the ovary. In: (ed. by) R. D. GREEP and E. B. AsTwOOD: Handbook of physiology, Sec. 7, Vol 2. Amer. Physiol. Soc., Washington, 1973 (p. 261-316).

Spanel-Borowsky, K., W. Amselgruber and F. SinoWATZ: Capillary sprouts in ovaries of immature superstimulated golden hamster: a SEM study of microcorrosion casts. Anat. Embryol. 176: 387-391 (1987).

VAn Blerkom, J. and P. M. MotTa: A scanning electron microscopy study of the luteo-follicular complex. III. Repair of ovulated follicle and the formation of the corpus luteum. Cell Tiss. Res. 189: 131-153 (1978).

: The cellular basis of mammalian reproduction. Urban \& Schwarzenberg, Baltimore-Munich, 1979 (p. 53-107).

Dr. Guido MACCHIARELLI

Department of Anatomy

University of Rome "La Sapienza"

Via A. Borelli 50

0061, Rome, Italy

Tel. $-39-6-4462623$

Fax -39-6-4452349 